\title{
Studies on Milk Yield, Milk Composition, Circulating Hormones, Energy Metabolites and Biochemical Parameters during Complete Lactation in Sahiwal Cows
}

\author{
K. B. Bahiram ${ }^{*}$, J. R. Khan ${ }^{2}$, N. E. Gade ${ }^{2}$, M. K. Gendley ${ }^{3}$, \\ M. S. Patil ${ }^{4}$ and J. Kumarsamy ${ }^{5}$
}

${ }^{1}$ Department of Veterinary Physiology, ${ }^{4}$ Department of ARGO, Nagpur Veterinary College, MAFSU, Nagpur-440006 (M. S.), India

${ }^{2}$ Department of Veterinary Physiology and Biochemistry, ${ }^{3}$ Department of Animal Nutrition, College of Veterinary Science \& A. H., Anjora, Durg - 491001(C. G.), India

${ }^{5}$ Radiation Medicine Center, Tata Memorial Hospital, Annex Parel, Mumbai-440012 (M. S.), India

*Corresponding author

\section{A B S T R A C T}

K e y w o r d s
$\begin{aligned} & \text { Sahiwal cows, } \\ & \text { lactation, MY, } \\ & \text { Composition, SCC, } \\ & \text { BCS, Hormones, } \\ & \text { Blood metabolites, } \\ & \text { Biochemical } \\ & \text { parameters }\end{aligned}$
Article Info
Accepted:
12 August 2020
Available Online:
10 September 2020

The present study was carried out on 07 Sahiwal lactating cows, which were kept under standard feed and managerial conditions during the experimental period in complete lactation. The milk composition was determined by automatic milk analyzer for fat, protein, lactose and SNF and milk yield was recorded for each sampling day. Somatic cells counts (SCC) was enumerated by standard method and BCS was recorded at fortnightly interval of all the experimental animals. The blood samples were collected on $7^{\text {th }}$ day after parturition and thereafter at fortnightly intervals till complete lactation from each animals and the serum was separated out and kept in aliquots for estimation of hormones, metabolites and biochemical parameters. The blood glucose concentration was immediately determined in fresh blood. The profile of metabolic hormones viz. $\mathrm{T}_{3}, \mathrm{~T}_{4}$, Insulin and GH, blood metabolites viz. blood glucose and NEFA and the biochemical profile viz. calcium, phosphorus and magnesium were determined during various stages of lactation. The average Lactation length was $294.71 \pm 5.23$ in Sahiwal cows. There was highly significant $(\mathrm{P}<0.01)$ difference in MY, Fat, BCS, $\mathrm{T}_{3}, \mathrm{~T}_{4}$, Insulin, GH, Glucose, $\mathrm{Ca}, \mathrm{P}$ and $\mathrm{Mg}$ concentration and significant $(\mathrm{P}<0.05)$ difference in SCC and NEFA concentration during various days of sampling during complete lactation in Sahiwal cows. However, there was non significant observed in Protein, Lactose and SNF \% during various days of sampling during complete lactation in Sahiwal cows. The relationship of these hormones, metabolites and biochemical parameters will help to understand the role of each of them in modulating the complete lactation of cows.

\section{Introduction}

All the major milk constituents are synthesized in the udder from various precursors which are absorbed selectively from the blood. The cow's diet is the ultimate source of most of material used in milk synthesis, and alteration in the amount and type of food affects both milk yield and composition. Milk is an important source of 
protein, minerals and vitamins. Milk protein contains more essential amino acids than any other natural food. Solid not fat includes non fatty constituents of milk like protein, minerals and other minor milk constituents. When nutritive value of milk protein and other non-fatty constituents especially calcium and vitamins are concerned, SNF content has its own importance. Total solids in milk are the function of different milk constituents. The sum of all the milk constituents measured in percentage result in total solids percentage in milk. The importance of protein is widely recognized, as they serve a variety of function from structure to reproduction in living organisms.

The nutrient requirements in late pregnancy, and particularly the nutrient demand for lactation, call for a coordination of the biological processes in different tissues resulting in metabolic changes that try to ensure that the cow's genetic potential for milk yield is exploited concurrently with maintenance of the homeostasis physiological parameters (Ingvartsen, 2006). After parturition, the maintenance of lactation is regulated by the number of hormones like $\mathrm{GH}$, Insulin, Prolactin, $\mathrm{T}_{4}$ and $\mathrm{T}_{3}$, which not only affect circulatory levels of blood metabolites but also the yield and composition of milk in cattle, buffaloes and goats (Jindal and Ludri, 1994; Singh and Ludri, 2002).

Glucose and non-esterified fatty acids (NEFA) have been used to access energy status of ruminant animals (Khan, 1998). Lactating dairy cows in positive energy balance have greater reproductive function than cows in negative energy balance (Spicer et al., 1990). The body condition score (BCS) system is a subjective scoring method of evaluating the energy reserves of dairy animals which provides a better understanding of biological relationship between body fat, milk production and reproduction that helps in adopting the optimum managemental practices to derive maximum production and maintain better health status. Somatic cell count (SCC) is being used as an index of inflammatory condition of udder. These are secreted during normal course of lactation in milk and therefore valid indicator of abnormal milk secretion, milk composition and mammary disease in dairy animals (Singh and Ludri, 2001). Therefore the increased somatic cell count (SCC) represents the response of udder tissue to the presence of pathogens causing the inflammation of the udder called mastitis (Pyorarla, 2003). Minerals are indispensable for growth, reproduction and health of animals. They are important for growth of most organs, particularly for mineralisation of bone network. Their distribution and status varies with different physiological conditions, viz. neonatal period, pre pubertal period, pubertal period, post pubertal stages, oestrous cycle, pregnancy and lactation (Pukan et al., 2000). It is an important attribute as it forms the basis for assessing future milk yield, milk composition and also in making economic and market decisions in farm animals.

\section{Materials and Methods}

The study was carried out in the herd of 07 Sahiwal lactating animals from Bull Mother Experimental Farm (BMEF), Veterinary College Anjora, Durg. The animals having BCS between 2.5 to 3.5 score and $2^{\text {nd }}$ to $4^{\text {th }}$ parity were selected. The milk composition was determined by automatic milk analyzer (Lactostar, Funky Gerber, Germany make) for fat, protein, lactose and SNF, and milk yield was recorded for each sampling day. Somatic cells count (SCC) was enumerated by standard method as per Singh and Dang (2002) and BCS was recorded at fortnightly interval of all the experimental animals. Scoring system of 1 to 5 point scale using 
0.25 increments for HF crossbred cows was recorded as per Ferguson et al., (1994) and Elanco (1996). Hormone analysis of $T_{3}, T_{4}$ and Insulin concentration in serum was determined by Radioimmunoassay kit supplied by BRIT, BARC, Mumbai and GH by RIA method (Khan and Ludri 2002). The blood glucose concentration was analyzed immediately after collection of blood by Accu-check glucometer. The serum NEFA concentration was determined by extraction method (chloroform:heptane: methanol, 49:49:2) as per Shipe et al., (1980), modified by Khan and Ludri (2002). The serum Ca, P $\& \mathrm{Mg}$ was determined by semi auto analyzer using biochemical kit. The statistical analysis of data was carried out using Analysis of Variance for comparison among various stages of lactation within each genetic group. In significant differences among various stages of lactation was analyzed following Duncan's Multiple Range Test. The Interrelationship among milk yield, composition, hormones, blood metabolites, biochemical parameters and SCC was studied by simple correlation coefficients. Overall above data was analyzed as per standard method of Snedecor and Cochran $8^{\text {th }}$ Ed. (1994) and SPSS (2015) for Windows Release 20.0 Version. SPSS Inc., USA.

\section{Results and Discussion}

\section{Milk yield and milk composition}

Mean \pm S. E. values of milk yield, milk composition, SCC and BCS during complete lactation in HF crossbred cows in Table 1

The mean value of milk yield $(\mathrm{Kg})$ ranges from $2.50 \pm 0.50$ to $4.71 \pm 0.38 \mathrm{Kg} /$ day during complete lactation in Sahiwal cows. The milk yield from day 7 increases up to day 35 and then there was slight declined up to day 63, there after it increases up to day 175 of lactation and there after declined was observed during late lactation up to 315 days of lactation. Bajwa et al., (2004), Epaphras et al., (2004) and Bahiram et al., (2018 $)$ reported average milk production throughout lactation stages and observed decreasing trend of milk yield as lactation advances. Broucek et al., (2009), and Kumaresan (2013, 2014) also reported significant effect in stages of lactation.

Mean value of milk fat $\%$ ranges from $2.59 \pm$ 0.30 to $5.10 \pm 0.17 \%$ during complete lactation in Sahiwal cows. The milk fat $\%$ decreases from day 7 up to day 21 and then there was slightly increased up to day 119 and then slight decrease on day 133 and thereafter increases up to day 217 and slight decrease day 231of lactation and then shows slightly variation till day 301 and then increase was observed. Similar findings were observed by Yadav et al., (1991) and Sudhakar et al., (2013). Whereas, Kumaresan (2013) and Bahiram et al., $\left(2018^{\mathrm{b}}\right)$ reported the range of 3.43 to 4.22 percent in different stages of lactation. As in dairy cows the most variables constituents of milk is its butter fat content which depends upon many factors, hence variability has found by different workers. However most of studies (Chawla and Mishra, 1976; Arora and Gupta, 1969) showed that normal value of fat percentage for Indian breeds ranged from 4.35 to 5.45 percent. Variation recorded by different workers and results of this study indicate that secretion of fat is a complex phenomenon, influenced by interplay of various factors like components of climatic elements, nutritional and physiological status of animals. The lowering of fat content during early part of lactation was perhaps due to higher quantity of milk produced during this period. Fat content increased markedly at the end of lactation, when the milk yield was low. It might be possible that feeding of more concentrate mixture during early lactation, 
increases production of propionate which is not a high fat precursor and hence results in low fat in milk.

The mean values of protein $\%$ ranges from $3.49 \pm 0.05$ to $3.80 \pm 0.09 \%$ during complete lactation and there were no significant variation was observed throughout lactation in Sahiwal cows. Similarly finding were observed by Saxena et al., (1997), Bhonsle et al., (2013) and Bahiram et al., (2018 ${ }^{\mathrm{b}}$ ) found that milk protein content varied significantly with stage of lactation. From the above findings it is clear that protein $\%$ was estimated in higher quantity in milk of cows in their advanced stage of lactation.

The mean value of lactose $\%$ ranges from $5.30 \pm 0.12$ to $5.82 \pm 0.03 \%$ during complete lactation in Sahiwal cows and statistically showed no significant variation throughout complete lactation. This finding is almost same with the results of Rook and Campling (1965) who reported only 5.04 percent lactose in Sahiwal cows. Since very little information is available on this milk constituent in indigenous cows, hence no comparison could be made. However lactose was found to as 4.50 and 4.52 in cross bred cattle as reported by Mathapati and Bhat (1988) and Voigtlander and Bothen (1979) and contrary report by Sharma et al., (1990) and Yogi et al., (2017) lactose \% increased in first three months of lactation.

Mean values of SNF \% ranges from $9.48 \pm$ 0.12 to $10.09 \pm 0.17 \%$ in Sahiwal cows during complete lactation. The pattern showed no significant variation throughout lactation. It was higher than the value reported by other workers. Similar findings were observed by Singh (1979) and Kaushik (1970) found overall mean of SNF contents as 8.82 in Sahiwal cows. Sharma et al., (2002) and Bahiram et al., $\left(2018^{\mathrm{b}}\right)$ who reported 8.75 percent SNF in crossbred cows. The higher
SNF percentage in present study might be due to better managemental practices and genetic potential of the herd. It is also interesting to note that fat and TS content were also increasing from early to late stage of lactation suggesting close association between these milk constituents. Nigam and Bector (1991) also confirmed above observations Venkatachelapati and Iype (1998) did not observed any specific trends of SNF during advancement of lactation. Jacob et al., (2014) studied in Gir and Jaffarabadi buffaloes no significant difference was observed between months of lactation.

The mean values of SCC ranges from $1.05 \pm$ 0.12 to $1.72 \pm 0.24\left(\mathrm{X} 10^{5}\right.$ cells $\left./ \mathrm{ml}\right)$ in Sahiwal cows during complete lactation. The pattern of SCC is indicated that varies slightly up to day 203 and then slightly increases till the end of lactation. Almost similar finding was observed by Kennedy et al., (1982) and Schutz et al., (1990) who reported SCC score high in beginning stages of lactation and contrary report by Kataria and Kataria (2006), Kamboz et al., (2007) and Kumaresen (2013) SCC was observed significant high in late lactation than early and mid lactation stages. Above results are with close agreement with result of Oudah (2009) who reported slightly increased in first four months than declined gradually end of lactation. Ouedraogo et al., (2008) found that the low milk yield was associated to higher somatic cell count. Weglarz et al., (2008) indicated that mean SCC was increased along with the cow's age. The SCC level was found highest in early stage of lactation.

The mean values of BCS during complete lactation in Sahiwal cows ranges from $2.68 \pm$ 0.14 to $3.57 \pm 0.17$. The pattern of Sahiwal cows from day 7 declined up to day 217 and thereafter slight increases till end of lactation. Similar results were also recorded by Ferguson (1996) and Broster and Broster 
(1998) who reported decrease 0.5 units first 2 to 3 months of lactation and slow recording in mid and late lactation. Higher producing cows tend to have lower BCS indicating that nutrients are partitioned towards milk production rather than increasing body reserves recorded by Dechow, et al., (2003). Rao and Anitha (2004) reported that high producing cows in one lactation often have low BCS in the next lactation because of excessive loss of body reserves during the lactation of high production. Fat cows tend to lose more body condition during early lactation than thin cows. Thin cows have been shown to gain body condition during early lactation in similar finding recorded by Garnsworthy and Topps (1982) and Gearhart et al., (1990). Treacher et al., (1986) and Balakrishnan, et al., (1997) reported moderate increase in condition score at calving (BCS 2 to 3) will lead to significant improvement in milk yield, but score above 3.5 at parturition was detrimental to milk production. However, contrary finding by Ruegg and Milton (1995) did not find any effect of condition score at calving on peak and 305 days milk yield. Schroder and Staeufenbiel (2006) and Domecq et al., (1997) observed that change in BCS during the first month of lactation has a stronger influence on milk yield than the condition at parturition and thus loss of body condition has been associated with increased milk yield.

\section{Hormonal parameters}

\section{Mean \pm S. E. Values of Hormonal parameters during complete lactation in HF crossbred cows (Table 2)}

The mean values of $\mathrm{T}_{3}$ ranges from $1.23 \pm$ 0.10 to $2.02 \pm 0.13 \mathrm{ng} / \mathrm{ml}$ during complete lactation in Sahiwal cows showed significant $(\mathrm{P}<0.01)$ variation are presented in Table 2 The pattern of $\mathrm{T}_{3}$ from day 7 increases up to day 21 and then decreases trend up to day 63.
From day 77 onwards the values continuously increased up to day 203 and thereafter day 217 from fluctuation was noticed up to end of lactation. Similar findings were observed by Singh and Ludri (2002) and Bahiram et al., $\left(2018^{\mathrm{a}}\right)$ who noted that higher value during early stage of lactation. However, contrary finding were recorded by Dalvi et al., (1995) who reported low $T_{3}$ concentration before parturition and followed by subsequent increase on day of parturition and declined after calving. Deshmukh and Mantri (1997) reported that $\mathrm{T}_{3}$ concentration varied non significantly and remain almost same in various stages of lactation.

The mean values of serum $\mathrm{T}_{4}$ level ranges from $29.00 \pm 3.52$ to $77.57 \pm 14.46 \mathrm{ng} / \mathrm{ml}$ during complete lactation in Sahiwal cows showed significant $(\mathrm{P}<0.01)$ variation. The values showed from day 7 decreasing up to day 49 and then increasing pattern up to day 119 and thereafter declined was observed during late lactation. Similar finding were observed by Singh and Ludri (2002) Bahiram et al., $\left(2018^{\mathrm{a}}\right)$ who reported higher $\mathrm{T}_{4}$ value during early stage of lactation. However, Dalvi et al., (1995) reported low concentration of $\mathrm{T}_{4}$ before parturition, increase on day of parturition and declined after calving. Deshmukh and Mantri (1997) reported non significant changes in $T_{4}$ concentration in various stages of lactation.

The mean values of serum Insulin level ranges from $10.80 \pm 1.09$ to $43.33 \pm 12.73$ $\mu \mathrm{U} / \mathrm{ml}$ during complete lactation in Sahiwal cows and statistically highly $(\mathrm{P}<0.01)$ significant variation are presented in Table 2. The pattern was showed increasing level up to day 91 and then there was slight decreases up to day 245 and then increases up to end of lactation. Similar findings of higher value during early stage of lactation were observed by Jindal and Ludri (1994), Jindal and Ludri $\left(1990^{\mathrm{b}}\right)$ and Singh and Ludri (2002). 
However, Nagre et al., (2013) reported that Insulin level differed significantly among the groups.

The mean values of serum GH level ranges from $2.85 \pm 0.55$ to $7.99 \pm 1.25 \mathrm{ng} / \mathrm{ml}$ during complete lactation in Sahiwal cows showed significant $(\mathrm{P}<0.01)$ variation. The levels of GH was initially high and then declined up to day 63 and then slightly increases up to day 133 and again slight declined up to day 203 and then increase day 217 and thereafter pattern was declined up to the end of lactation. Similar finding of higher value during early stage of lactation were observed by Jindal and Ludri $\left(1990^{\mathrm{a}}\right)$, Singh and Ludri (2002) and Bahiram et al., (2018 ${ }^{\mathrm{a}}$.

\section{Blood metabolites and biochemical parameters}

\section{Mean \pm S. E. Values of Blood metabolites and Biochemical parameters during complete lactation in HF crossbred cows (Table 3)}

The pattern of blood glucose level presented in Table 3 and ranges from $49.86 \pm 2.32$ to $64.86 \pm 2.82 \mathrm{mg} / \mathrm{dl}$ during complete lactation in Sahiwal cows. The mean values of these breed showed increasing trend till the end of lactation. However in Sahiwal cows mean values showed highly significant $(\mathrm{P}<0.01)$ variation during complete lactation. Similar finding were observed by Overton (2003) and Dahate, et al., (2004) who reported significantly high blood glucose concentration in dry cows as compare to lactating cows. Mishra, et al., (2007) and Khan, et al., (2011) noted non significant change in glucose concentration in lactation. The end of pregnancy and the beginning of lactation, represent a time when there is a massive increase in need for glucose. This poses an enormous challenge for the liver that has to synthesize all of this glucose from propionate and amino acids as well as a challenge for other tissues and organs that have to adapt to a reduction of glucose availability. Glucose is an equally important energy source for the ovary and the reduced glucose availability in the beginning of lactation can negatively impact the reestablishment of ovarian activity after calving (Rawat et al., 2006).

The mean values of serum NEFA level ranges from $0.12 \pm 0.01$ to $0.88 \pm 0.28 \mathrm{mMol} / \mathrm{L}$ during complete lactation in Sahiwal cows showed significant $(\mathrm{P}<0.05)$ variation. The level was initially decreases up to day 35 and gradually increases up to day 77 and then again trend was decreases up to day 161 and then increase day 175 then slightly declined up to day 245 and then slight increases up to day 273 and finally decreases up to the end of lactation. Similar finding were observed by Khan, et al., (2011), Bruno, et al., (2012) and Piccione, et al., (2012).

The mean values of serum $\mathrm{Ca}$ level concentration ranges from $7.93 \pm 0.53$ to $10.66 \pm 0.70 \mathrm{mg} / \mathrm{dl}$ during complete lactation in Sahiwal cows. The trend was decreased from day 7 to day 49 and then slightly varies up to day 133 and thereafter slightly increased was observed during late lactation up to 315 days in Sahiwal cows. Similar finding were observed by Pradhan and Chakraborti (1986) and Kulkarni et al., (1993) and Piccoine et al., (2012) reported significant increases all stages of lactation. Whereas, Manzoor et al., (1994) who recorded that blood plasma $\mathrm{Ca}$ values $4.60 \mathrm{mEq} / \mathrm{L}, 4.71 \mathrm{mEq} / \mathrm{L}$ in $\mathrm{mid}$ and 5.00 $\mathrm{mEq} / \mathrm{L}$ in late lactation with a significant increase in late lactation. Kulkarni et al., (1983) and Shrikhande et al., (2001) noted nonsignificant effect of parity of animals on calcium concentration.

The mean values of serum $\mathrm{P}$ level ranges from $3.58 \pm 0.21$ to $5.93 \pm 0.80 \mathrm{mg} / \mathrm{dl}$ during complete lactation in Sahiwal cows. 
Table.1 Mean \pm S. E. Values of Milk Yield, Milk Composition, SCC and BCS during complete lactation in Sahiwal cows

\begin{tabular}{|c|c|c|c|c|c|c|c|c|c|c|c|c|c|c|c|c|c|c|c|c|c|c|c|c|}
\hline Days & 7 & 21 & 35 & 49 & 63 & 77 & 91 & 105 & 119 & 133 & 147 & 161 & 175 & 189 & 203 & 217 & 231 & 245 & 259 & 273 & 287 & 301 & 315 & $\begin{array}{c}\text { Level of } \\
\text { significa } \\
\text { nt }\end{array}$ \\
\hline $\begin{array}{c}\text { Milk } \\
\text { Yield } \\
\text { (Kg/day) }\end{array}$ & $\begin{array}{c}3.00^{\mathrm{cd}} \\
\pm \\
0.39\end{array}$ & 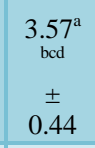 & $\begin{array}{c}\begin{array}{c}3.93 \\
\text { bcd } \\
\pm \\
0.23\end{array} \\
\end{array}$ & $\begin{array}{c}\begin{array}{c}3.57^{\mathrm{a}} \\
\mathrm{bcd}\end{array} \\
\pm \\
0.30\end{array}$ & $\begin{array}{c}3.43 \\
\text { bcd } \\
\pm \\
0.28\end{array}$ & $\begin{array}{c}\begin{array}{c}3.71^{\mathrm{a}} \\
\mathrm{bc}\end{array} \\
\pm \\
0.15\end{array}$ & $\begin{array}{c}3.86 \\
\text { abc } \\
\pm \\
0.34\end{array}$ & $\begin{array}{c}\begin{array}{c}3.71^{\mathrm{a}} \\
\mathrm{bc}\end{array} \\
\pm \\
0.15\end{array}$ & $\begin{array}{c}4.00 \\
\text { abc } \\
\pm \\
0.22 \\
\end{array}$ & $\begin{array}{c}4.00 \\
\text { abc } \\
\pm \\
0.19\end{array}$ & $\begin{array}{c}4.21 \\
\text { abc } \\
\pm \\
0.32\end{array}$ & $\begin{array}{c}4.29 \\
\mathrm{ab} \\
\pm \\
0.29\end{array}$ & $\begin{array}{c}4.71 \\
\mathrm{a} \\
\pm \\
\pm \\
0.38\end{array}$ & $\begin{array}{c}4.43 \\
\mathrm{ab} \\
\pm \\
0.43\end{array}$ & $\begin{array}{c}4.43 \\
\mathrm{ab} \\
\pm \\
0.44\end{array}$ & $\begin{array}{c}4.57^{\mathrm{ab}} \\
\pm \\
0.38\end{array}$ & $\begin{array}{c}4.57^{\mathrm{a}} \\
\mathrm{b} \\
\pm \\
0.40\end{array}$ & $\begin{array}{c}\begin{array}{c}3.91^{\mathrm{a}} \\
\mathrm{bc}\end{array} \\
\pm \\
0.32\end{array}$ & $\begin{array}{c}\begin{array}{c}3.50^{\mathrm{a}} \\
\text { bcd }\end{array} \\
\pm \\
0.33\end{array}$ & $\begin{array}{c}\begin{array}{c}3.50^{\mathrm{a}} \\
\text { bcd }\end{array} \\
\pm \\
0.39\end{array}$ & $\begin{array}{c}3.50^{\mathrm{ab}} \\
\pm \\
\pm .32\end{array}$ & $\begin{array}{c}2.50^{\mathrm{d}} \\
\pm \\
0.50\end{array}$ & $\begin{array}{c}3.00^{\mathrm{c}} \\
\mathrm{d} \\
\pm \\
0.34\end{array}$ & $* *$ \\
\hline $\begin{array}{l}\text { Fat } \\
(\%)\end{array}$ & $\begin{array}{c}2.90^{\mathrm{cd}} \\
\pm \\
0.41\end{array}$ & $\begin{array}{c}2.59^{c} \\
d \\
\pm \\
0.30\end{array}$ & $\begin{array}{c}3.62 \\
\text { bcd } \\
\pm \\
0.31\end{array}$ & $\begin{array}{c}\begin{array}{c}3.70^{\mathrm{a}} \\
\text { bcd }\end{array} \\
\pm \\
0.24\end{array}$ & $\begin{array}{c}3.95 \\
\text { abc } \\
\pm \\
0.38\end{array}$ & $\begin{array}{c}\begin{array}{c}3.74^{\mathrm{a}} \\
\text { bcd }\end{array} \\
\pm \\
0.60\end{array}$ & $\begin{array}{c}4.02 \\
\text { abc } \\
\pm \\
0.21\end{array}$ & $\begin{array}{c}3.80^{\mathrm{a}} \\
\text { bcd } \\
\pm \\
0.29\end{array}$ & $\begin{array}{c}3.95 \\
\mathrm{abc} \\
\pm \\
0.26\end{array}$ & $\begin{array}{c}3.64 \\
\text { bcd } \\
\pm \\
0.21\end{array}$ & $\begin{array}{c}4.21 \\
\text { abc } \\
\pm \\
0.28\end{array}$ & $\begin{array}{c}4.40 \\
a \\
\pm \\
\pm .25\end{array}$ & $\begin{array}{c}4.21 \\
\mathrm{ab} \\
\pm \\
0.26\end{array}$ & $\begin{array}{c}4.13 \\
\text { abc } \\
\pm \\
0.20\end{array}$ & $\begin{array}{c}4.32 \\
\mathrm{a} \\
\pm \\
0.27\end{array}$ & $\begin{array}{c}4.32^{\mathrm{a}} \\
\pm \\
0.27\end{array}$ & $\begin{array}{c}\begin{array}{c}3.91^{\mathrm{a}} \\
\mathrm{bc} \\
\pm \\
0.20\end{array}\end{array}$ & $\begin{array}{c}4.22^{\mathrm{a}} \\
\mathrm{b} \\
\pm \\
0.20\end{array}$ & $\begin{array}{c}4.39^{\mathrm{a}} \\
\pm \\
0.19\end{array}$ & $\begin{array}{c}4.35^{\mathrm{a}} \\
\pm \\
0.16\end{array}$ & $\begin{array}{c}4.14^{\mathrm{ab}} \\
\pm \\
\pm \\
0.28\end{array}$ & $\begin{array}{c}3.67^{\mathrm{b}} \\
\pm \\
0.39\end{array}$ & $\begin{array}{c}5.10^{\mathrm{a}} \\
\pm \\
0.17\end{array}$ & $* *$ \\
\hline $\begin{array}{c}\text { Protein } \\
(\%)\end{array}$ & $\begin{array}{c}3.70 \\
\pm \\
0.09\end{array}$ & $\begin{array}{c}3.56 \\
\pm \\
0.04\end{array}$ & $\begin{array}{c}3.61 \\
\pm \\
0.05\end{array}$ & $\begin{array}{c}3.49 \\
\pm \\
0.05\end{array}$ & $\begin{array}{c}3.59 \\
\pm \\
0.04\end{array}$ & $\begin{array}{c}3.55 \\
\pm \\
0.04\end{array}$ & $\begin{array}{c}3.56 \\
\pm \\
0.05\end{array}$ & $\begin{array}{c}3.80 \\
\pm \\
0.09\end{array}$ & $\begin{array}{c}3.68 \\
\pm \\
0.10\end{array}$ & $\begin{array}{c}3.63 \\
\pm \\
0.04\end{array}$ & $\begin{array}{c}3.62 \\
\pm \\
0.05\end{array}$ & $\begin{array}{c}3.64 \\
\pm \\
0.04\end{array}$ & $\begin{array}{c}3.65 \\
\pm \\
0.04\end{array}$ & $\begin{array}{c}3.78 \\
\pm \\
0.09\end{array}$ & $\begin{array}{c}3.66 \\
\pm \\
0.03\end{array}$ & $\begin{array}{c}3.70 \\
\pm \\
0.07\end{array}$ & $\begin{array}{c}3.70 \\
\pm \\
0.08\end{array}$ & $\begin{array}{c}3.70 \\
\pm \\
0.09\end{array}$ & $\begin{array}{c}3.70 \\
\pm \\
0.09\end{array}$ & $\begin{array}{c}3.70 \\
\pm \\
0.08\end{array}$ & $\begin{array}{c}3.70 \\
\pm \\
0.07\end{array}$ & $\begin{array}{c}3.70 \\
\pm \\
0.09\end{array}$ & $\begin{array}{c}3.69 \\
\pm \\
0.08\end{array}$ & NS \\
\hline $\begin{array}{c}\text { Lactose } \\
(\%)\end{array}$ & $\begin{array}{c}5.72 \\
\pm \\
0.17\end{array}$ & $\begin{array}{c}5.55 \\
\pm \\
0.06\end{array}$ & $\begin{array}{c}5.48 \\
\pm \\
0.05\end{array}$ & $\begin{array}{c}5.42 \\
\pm \\
0.07\end{array}$ & $\begin{array}{c}5.57 \\
\pm \\
0.07\end{array}$ & $\begin{array}{c}5.56 \\
\pm \\
0.07\end{array}$ & $\begin{array}{c}5.56 \\
\pm \\
0.08\end{array}$ & $\begin{array}{c}5.78 \\
\pm \\
0.10 \\
\end{array}$ & $\begin{array}{c}5.59 \\
\pm \\
0.08\end{array}$ & $\begin{array}{c}5.69 \\
\pm \\
0.11\end{array}$ & $\begin{array}{c}5.65 \\
\pm \\
0.09\end{array}$ & $\begin{array}{c}5.73 \\
\pm \\
0.09 \\
\end{array}$ & $\begin{array}{c}5.74 \\
\pm \\
0.06\end{array}$ & $\begin{array}{c}5.74 \\
\pm \\
0.09 \\
\end{array}$ & $\begin{array}{c}5.71 \\
\pm \\
0.07\end{array}$ & $\begin{array}{c}5.62 \\
\pm \\
0.11\end{array}$ & $\begin{array}{c}5.74 \\
\pm \\
0.08\end{array}$ & $\begin{array}{c}5.79 \\
\pm \\
0.05\end{array}$ & $\begin{array}{c}5.71 \\
\pm \\
0.09 \\
\end{array}$ & $\begin{array}{c}5.82 \\
\pm \\
0.01\end{array}$ & $\begin{array}{c}5.77 \\
\pm \\
0.04\end{array}$ & $\begin{array}{c}5.82 \\
\pm \\
0.03\end{array}$ & $\begin{array}{c}5.30 \\
\pm \\
0.12\end{array}$ & NS \\
\hline $\begin{array}{l}\text { SNF } \\
(\%)\end{array}$ & $\begin{array}{c}10.04 \\
\pm \\
0.22\end{array}$ & $\begin{array}{c}9.64 \\
\pm \\
0.10\end{array}$ & $\begin{array}{c}9.66 \\
\pm \\
0.08\end{array}$ & $\begin{array}{c}9.48 \\
\pm \\
0.12\end{array}$ & $\begin{array}{c}9.55 \\
\pm \\
0.08\end{array}$ & $\begin{array}{c}9.58 \\
\pm \\
0.05\end{array}$ & $\begin{array}{c}9.71 \\
\pm \\
0.17\end{array}$ & $\begin{array}{c}9.71 \\
\pm \\
0.12\end{array}$ & $\begin{array}{c}9.80 \\
\pm \\
0.17\end{array}$ & $\begin{array}{c}9.87 \\
\pm \\
0.24\end{array}$ & $\begin{array}{c}9.94 \\
\pm \\
0.27\end{array}$ & $\begin{array}{c}9.99 \\
\pm \\
0.19\end{array}$ & $\begin{array}{c}9.91 \\
\pm \\
0.12\end{array}$ & $\begin{array}{c}10.0 \\
9 \\
\pm \\
0.17\end{array}$ & $\begin{array}{c}9.84 \\
\pm \\
0.14\end{array}$ & $\begin{array}{c}9.73 \\
\pm \\
0.15\end{array}$ & $\begin{array}{c}9.94 \\
\pm \\
0.11\end{array}$ & $\begin{array}{c}10.0 \\
1 \\
\pm \\
0.13\end{array}$ & $\begin{array}{c}9.66 \\
\pm \\
0.17\end{array}$ & $\begin{array}{c}9.97 \\
\pm \\
0.11\end{array}$ & $\begin{array}{c}9.97 \\
\pm \\
0.13\end{array}$ & $\begin{array}{c}9.96 \\
\pm \\
0.38\end{array}$ & $\begin{array}{c}10.0 \\
0 \\
\pm \\
0.11\end{array}$ & NS \\
\hline $\begin{array}{c}\text { SCC } \\
\left(X 1^{5}\right. \\
\text { cells/ml })\end{array}$ & $\begin{array}{c}1.28^{\mathrm{a}} \\
\pm \\
0.18\end{array}$ & $\begin{array}{c}1.41^{\mathrm{a}} \\
\pm \\
0.19\end{array}$ & $\begin{array}{c}1.06 \\
\mathrm{ab} \\
\pm \\
0.10\end{array}$ & $\begin{array}{c}1.20^{\mathrm{a}} \\
\pm \\
\pm \\
0.16\end{array}$ & $\begin{array}{c}1.56 \\
\mathrm{a} \\
\pm \\
0.30\end{array}$ & $\begin{array}{c}1.07^{\mathrm{a}} \\
\mathrm{b} \\
\pm \\
0.16\end{array}$ & $\begin{array}{c}1.42 \\
\mathrm{a} \\
\pm \\
0.18\end{array}$ & $\begin{array}{c}1.19^{\mathrm{a}} \\
\mathrm{b} \\
\pm \\
0.15\end{array}$ & $\begin{array}{c}1.23 \\
\mathrm{a} \\
\pm \\
0.26\end{array}$ & $\begin{array}{c}1.17 \\
\mathrm{ab} \\
\pm \\
0.12\end{array}$ & $\begin{array}{c}1.23 \\
\mathrm{a} \\
\pm \\
0.08\end{array}$ & $\begin{array}{c}1.19 \\
\text { ab } \\
\pm \\
0.18\end{array}$ & $\begin{array}{c}1.23 \\
a \\
\pm \\
0.14\end{array}$ & $\begin{array}{c}1.23 \\
\mathrm{a} \\
\pm \\
\pm .10\end{array}$ & $\begin{array}{c}1.05 \\
\mathrm{ab} \\
\pm \\
0.12\end{array}$ & $\begin{array}{c}1.10^{\mathrm{ab}} \\
\pm \\
0.04\end{array}$ & $\begin{array}{c}1.30^{\mathrm{a}} \\
\pm \\
0.14\end{array}$ & $\begin{array}{c}1.37^{\mathrm{a}} \\
\pm \\
0.25\end{array}$ & $\begin{array}{c}1.16^{\mathrm{a}} \\
\pm \\
0.12\end{array}$ & $\begin{array}{c}1.13^{\mathrm{a}} \\
\mathrm{b} \\
\pm \\
0.13\end{array}$ & $\begin{array}{c}1.47^{\mathrm{a}} \\
\pm \\
0.21\end{array}$ & $\begin{array}{c}1.33^{\mathrm{a}} \\
\pm \\
0.57\end{array}$ & $\begin{array}{c}1.72^{\mathrm{a}} \\
\pm \\
0.24\end{array}$ & $*$ \\
\hline BCS & $\begin{array}{c}3.57^{\mathrm{a}} \\
\pm \\
0.17\end{array}$ & $\begin{array}{c}3.57^{\mathrm{a}} \\
\pm \\
0.17\end{array}$ & $\begin{array}{c}3.57 \\
\mathrm{a} \\
\pm \\
0.17\end{array}$ & $\begin{array}{c}3.32^{\mathrm{a}} \\
\mathrm{b} \\
\pm \\
0.17\end{array}$ & $\begin{array}{c}3.32 \\
\text { ab } \\
\pm \\
0.17\end{array}$ & $\begin{array}{c}3.32^{\mathrm{a}} \\
\mathrm{b} \\
\pm \\
0.17\end{array}$ & $\begin{array}{c}3.11 \\
\text { ab } \\
\pm \\
0.17\end{array}$ & $\begin{array}{c}3.07^{\mathrm{a}} \\
\mathrm{b} \\
\pm \\
0.17\end{array}$ & $\begin{array}{c}3.07 \\
\mathrm{ab} \\
\pm \\
0.17\end{array}$ & $\begin{array}{c}3.07 \\
\text { ab } \\
\pm \\
0.17\end{array}$ & $\begin{array}{c}2.96 \\
\mathrm{ab} \\
\pm \\
0.16\end{array}$ & $\begin{array}{c}2.82 \\
\text { abc } \\
\pm \\
0.17\end{array}$ & $\begin{array}{c}2.82 \\
\text { abc } \\
\pm \\
0.17\end{array}$ & $\begin{array}{c}2.82 \\
\mathrm{abc} \\
\pm \\
0.17\end{array}$ & $\begin{array}{c}2.82 \\
\text { abc } \\
\pm \\
0.16\end{array}$ & $\begin{array}{c}2.68^{\mathrm{bc}} \\
\pm \\
0.14\end{array}$ & $\begin{array}{c}2.71^{b} \\
\pm \\
0.13\end{array}$ & $\begin{array}{c}2.75^{\mathrm{b}} \\
\mathrm{c} \\
\pm \\
0.13\end{array}$ & $\begin{array}{c}2.89^{\mathrm{a}} \\
\mathrm{bc} \\
\pm \\
0.16\end{array}$ & $\begin{array}{c}2.93^{\mathrm{a}} \\
\mathrm{b} \\
\pm \\
0.14\end{array}$ & $\begin{array}{c}2.90^{\mathrm{ab}} \\
\pm \\
0.13\end{array}$ & $\begin{array}{c}2.83^{\mathrm{a}} \\
\mathrm{bc} \\
\pm \\
0.22\end{array}$ & $\begin{array}{c}2.75^{b} \\
\pm \\
0.13\end{array}$ & $* *$ \\
\hline
\end{tabular}

Means ${ }^{\text {abcdefgh }}$ having different superscripts in row differ significantly

* Significance at $\mathrm{P}<0.05, * *$ Significance at $\mathrm{P}<0.01$ 


\section{Int.J.Curr.Microbiol.App.Sci (2020) 9(9): 1586-1599}

Table.2 Mean \pm S. E. Values of Hormonal parameters during complete lactation in Sahiwal cows

\begin{tabular}{|c|c|c|c|c|c|c|c|c|c|c|c|c|c|c|c|c|c|c|c|c|c|c|c|c|}
\hline Days & 7 & 21 & 35 & 49 & 63 & 77 & 91 & 105 & 119 & 133 & 147 & 161 & 175 & 189 & 203 & 217 & 231 & 245 & 259 & 273 & 287 & 301 & 315 & $\begin{array}{c}\text { Level of } \\
\text { signific } \\
\text { ant }\end{array}$ \\
\hline $\mathbf{T}_{3}(\mathbf{n g} / \mathrm{ml})$ & $\begin{array}{c}1.41^{\mathrm{abc}} \\
\pm \\
0.33\end{array}$ & $\begin{array}{c}1.55^{\mathrm{ab}^{\mathrm{b}}} \\
\pm \\
0.27\end{array}$ & $\begin{array}{c}1.35^{\mathrm{ab}} \\
\mathrm{c} \\
\pm \\
\pm .07\end{array}$ & $\begin{array}{c}1.28^{\mathrm{bc}} \\
\pm \\
0.07\end{array}$ & $\begin{array}{c}1.23^{c} \\
\pm \\
0.10\end{array}$ & $\begin{array}{c}1.59^{\mathrm{a}} \\
\mathrm{bc} \\
\pm \\
0.11\end{array}$ & $\begin{array}{c}1.49^{\mathrm{a}} \\
\mathrm{bc} \\
\pm \\
0.10\end{array}$ & $\begin{array}{c}1.61^{\mathrm{a}} \\
\mathrm{bc} \\
\pm \\
0.27\end{array}$ & $\begin{array}{c}1.65^{\text {abc }} \\
\pm \\
0.18\end{array}$ & $\begin{array}{c}1.64^{\mathrm{ab}} \\
\mathrm{c} \\
\pm \\
0.17\end{array}$ & $\begin{array}{c}1.79^{\mathrm{ab}} \\
\mathrm{c} \\
\pm \\
0.16\end{array}$ & $\begin{array}{c}1.83^{\mathrm{ab}} \\
\mathrm{c} \\
\pm \\
0.19\end{array}$ & $\begin{array}{c}1.80^{\mathrm{abc}} \\
\pm \\
0.20\end{array}$ & $\begin{array}{c}1.91^{\mathrm{ab}} \\
\pm \\
0.10\end{array}$ & $\begin{array}{c}1.90^{\mathrm{ab}} \\
\pm \\
0.13\end{array}$ & $\begin{array}{c}1.77^{\mathrm{abc}} \\
\pm \\
0.15\end{array}$ & $\begin{array}{c}1.93^{\mathrm{ab}} \\
\pm \\
0.18\end{array}$ & $\begin{array}{c}1.67^{\mathrm{abc}} \\
\pm \\
0.15\end{array}$ & $\begin{array}{c}2.02^{\mathrm{a}} \\
\pm \\
0.13\end{array}$ & $\begin{array}{c}1.66^{\mathrm{ab}} \\
\mathrm{c} \\
\pm \\
0.11\end{array}$ & $\begin{array}{c}1.95^{\text {ab }} \\
\pm \\
0.14\end{array}$ & $\begin{array}{c}1.44 \\
\text { abc } \\
\pm \\
0.22\end{array}$ & $\begin{array}{c}1.69^{\mathrm{ab}} \\
\mathrm{c} \\
\pm \\
0.15\end{array}$ & $* *$ \\
\hline $\mathrm{T}_{4}(\mathrm{ng} / \mathrm{ml})$ & $\begin{array}{c}41.43^{\text {bcde }} \\
\pm \\
6.19\end{array}$ & $\begin{array}{c}36.00 \\
\text { bcde } \\
\pm \\
4.14\end{array}$ & $\begin{array}{c}33.43 \\
\mathrm{cde} \\
\pm \\
3.70\end{array}$ & $\begin{array}{c}29.00^{\text {def }} \\
\pm \\
3.52\end{array}$ & $\begin{array}{c}55.7 \\
1^{\text {abcd }} \\
\pm \\
7.45\end{array}$ & $\begin{array}{c}48.57 \\
\text { bcde } \\
\pm \\
6.92\end{array}$ & $\begin{array}{c}54.0 \\
0^{\text {abcd }} \\
\pm \\
2.10\end{array}$ & & $\begin{array}{c}77.57^{\mathrm{a}} \\
\pm \\
14.46\end{array}$ & $\begin{array}{c}49.29 \\
\text { abcd } \\
\pm \\
7.58\end{array}$ & $\begin{array}{c}42.00 \\
\text { bcde } \\
\pm \\
4.69\end{array}$ & $\begin{array}{c}41.00 \\
\text { bcde } \\
\pm \\
6.74\end{array}$ & $\begin{array}{c}48.71^{b} \\
\text { cde } \\
\pm \\
6.02\end{array}$ & $\begin{array}{c}57.43^{\mathrm{a}} \\
\text { bcd } \\
\pm \\
8.81\end{array}$ & $\begin{array}{c}59.86^{\mathrm{abc}} \\
\pm \\
8.95\end{array}$ & $\begin{array}{c}52.86^{\text {abcd }} \\
\pm \\
10.44\end{array}$ & $\begin{array}{c}57.00^{\mathrm{ab}} \\
\pm \\
\pm \\
13.34\end{array}$ & $\begin{array}{c}64.57^{\mathrm{ab}} \\
\pm \\
10.15\end{array}$ & $\begin{array}{c}52.43 \\
\text { abcd } \\
\pm \\
6.81\end{array}$ & $\begin{array}{c}53.57^{\mathrm{a}} \\
\text { bcd } \\
\pm \\
9.71\end{array}$ & $\begin{array}{c}56.20^{\mathrm{a}} \\
\text { bcd } \\
\pm \\
\pm \\
11.24\end{array}$ & $\begin{array}{c}48.3 \\
3^{\text {abcd }} \\
\pm \\
11.1 \\
4\end{array}$ & $\begin{array}{c}50.00 \\
\text { abcd } \\
\pm \\
12.13\end{array}$ & $* *$ \\
\hline $\begin{array}{c}\text { Insulin } \\
(\mu \mathrm{U} / \mathrm{ml})\end{array}$ & $\begin{array}{l}16.07^{\text {cd }} \\
\pm \\
4.24\end{array}$ & $\begin{array}{c}10.80 \\
d \\
\pm \\
1.09\end{array}$ & $\begin{array}{c}15.79 \\
\text { cd } \\
\pm \\
1.86\end{array}$ & $\begin{array}{c}16.43^{\text {cd }} \\
\pm \\
3.24\end{array}$ & $\begin{array}{c}16.8 \\
6^{\text {cd }} \\
\pm \\
4.23\end{array}$ & $\begin{array}{c}\underset{c d}{20.14} \\
\pm \\
3.45\end{array}$ & $\begin{array}{c}34.1 \\
4^{\mathrm{ab}} \\
\pm \\
6.78\end{array}$ & $\begin{array}{c}24.2 \\
9^{\mathrm{bc}} \\
\pm \\
6.24\end{array}$ & $\begin{array}{c}22.29^{\mathrm{bc}} \\
\pm \\
4.97\end{array}$ & $\begin{array}{c}\underset{\mathrm{bc}}{21.43} \\
\pm \\
3.13\end{array}$ & $\begin{array}{c}\underset{c d}{15.29} \\
\pm \\
2.81\end{array}$ & $\begin{array}{c}16.86^{c} \\
\pm \\
\pm \\
2.75\end{array}$ & $\begin{array}{c}18.71^{\mathrm{c}} \\
\mathrm{d} \\
\pm \\
2.24\end{array}$ & $\begin{array}{c}17.29^{c} \\
d \\
\pm \\
1.78\end{array}$ & $\begin{array}{c}15.00^{\mathrm{cd}} \\
\pm \\
1.23\end{array}$ & $\begin{array}{c}16.29^{\text {cd }} \\
\pm \\
1.85\end{array}$ & $\begin{array}{c}15.29^{\text {cd }} \\
\pm \\
1.02\end{array}$ & $\begin{array}{c}16.43^{\text {cd }} \\
\pm \\
1.39\end{array}$ & $\begin{array}{c}39.29 \\
\mathrm{a} \\
\pm \\
5.31\end{array}$ & $\begin{array}{c}46.00^{\mathrm{a}} \\
\pm \\
4.26\end{array}$ & $\begin{array}{c}26.40^{c} \\
\pm \\
5.78\end{array}$ & $\begin{array}{c}43.3 \\
3^{\mathrm{a}} \\
\pm \\
12.7 \\
3\end{array}$ & $\begin{array}{c}41.00 \\
\mathrm{a} \\
\pm \\
4.21\end{array}$ & $* *$ \\
\hline$\underset{(\mathbf{n g} / \mathbf{m l})}{\mathbf{G H}}$ & $\begin{array}{c}7.99^{\mathrm{a}} \\
\pm \\
1.25\end{array}$ & $\begin{array}{c}6.68^{\mathrm{ab}} \\
\pm \\
0.99\end{array}$ & $\begin{array}{c}4.92^{\mathrm{ab}} \\
\mathrm{c} \\
\pm \\
1.15\end{array}$ & $\begin{array}{c}4.92^{\mathrm{abc}} \\
\pm \\
0.63\end{array}$ & $\begin{array}{c}2.85^{\mathrm{c}} \\
\mathrm{de} \\
\pm \\
0.55\end{array}$ & $\begin{array}{c}\begin{array}{c}3.60^{b} \\
\text { cde }\end{array} \\
\pm \\
0.62\end{array}$ & $\begin{array}{c}3.94^{\mathrm{b}} \\
\mathrm{cd} \\
\pm \\
0.79\end{array}$ & $\begin{array}{c}3.94^{\mathrm{b}} \\
\mathrm{cd} \\
\pm \\
0.70\end{array}$ & $\begin{array}{c}4.19^{\text {bcd }} \\
\pm \\
0.91\end{array}$ & $\begin{array}{c}4.77^{\mathrm{ab}} \\
\mathrm{cd} \\
\pm \\
1.59\end{array}$ & $\begin{array}{c}4.33^{b c} \\
\pm \\
\pm \\
1.11\end{array}$ & $\begin{array}{c}4.08^{\mathrm{bc}} \\
\mathrm{d} \\
\pm \\
1.51\end{array}$ & $\begin{array}{c}3.42^{\mathrm{bc}} \\
\mathrm{de} \\
\pm \\
0.92\end{array}$ & $\begin{array}{c}3.63^{\text {bcd }} \\
\pm \\
\pm \\
1.46\end{array}$ & $\begin{array}{c}3.47^{\text {bcde }} \\
\pm \\
0.62\end{array}$ & $\begin{array}{c}5.90^{\mathrm{abc}} \\
\pm \\
1.29\end{array}$ & $\begin{array}{c}4.90^{\mathrm{abc}} \\
\pm \\
0.53\end{array}$ & $\begin{array}{c}4.04^{\text {bcd }} \\
\pm \\
0.81\end{array}$ & $\begin{array}{c}5.89^{\text {ab }} \\
\text { c } \\
\pm \\
0.84\end{array}$ & $\begin{array}{c}5.71^{\mathrm{ab}} \\
\mathrm{c} \\
\pm \\
0.99\end{array}$ & $\begin{array}{c}4.34^{\text {cde }} \\
\pm \\
1.50\end{array}$ & $\begin{array}{c}3.33 \\
\text { cde } \\
\pm \\
0.97\end{array}$ & $\begin{array}{c}3.28^{\text {cd }} \\
{ }^{ \pm} \\
0.56\end{array}$ & $* *$ \\
\hline
\end{tabular}

Means ${ }^{\text {abcdefg }}$ having different superscripts in row differ significantly

* Significance at $\mathrm{P}<0.05$, ** Significance at $\mathrm{P}<0.01$ 
Table.3 Mean \pm S. E. Values of Blood metabolites and Biochemical parameters during complete lactation in Sahiwal cows

\begin{tabular}{|c|c|c|c|c|c|c|c|c|c|c|c|c|c|c|c|c|c|c|c|c|c|c|c|c|}
\hline Days & 7 & 21 & 35 & 49 & 63 & 77 & 91 & 105 & 119 & 133 & 147 & 161 & 175 & 189 & 203 & 217 & 231 & 245 & 259 & 273 & 287 & 301 & 315 & $\begin{array}{c}\text { Level of } \\
\text { significant }\end{array}$ \\
\hline $\begin{array}{l}\text { Glucose } \\
\text { (mg/dl) }\end{array}$ & $\begin{array}{c}49.86^{\mathrm{ab}} \\
\pm \\
2.32\end{array}$ & $\begin{array}{c}55.43^{\mathrm{ab}} \\
\pm \\
2.11\end{array}$ & $\begin{array}{c}54.00^{\mathrm{ab}} \\
\pm \\
1.66\end{array}$ & $\begin{array}{c}56.43^{\mathrm{ab}} \\
\pm \\
1.81\end{array}$ & $\begin{array}{c}55.43^{\mathrm{ab}} \\
\pm \\
1.93\end{array}$ & $\begin{array}{c}53.71^{\mathrm{ab}} \\
\pm \\
2.29\end{array}$ & $\begin{array}{c}55.30^{\mathrm{ab}} \\
\pm \\
3.83\end{array}$ & $\begin{array}{c}58.57^{\mathrm{ab}} \\
\pm \\
2.49\end{array}$ & $\begin{array}{c}55.43^{\mathrm{ab}} \\
\pm \\
2.90\end{array}$ & $\begin{array}{c}59.29^{\mathrm{ab}} \\
\pm \\
2.80\end{array}$ & $\begin{array}{c}58.43^{\mathrm{ab}} \\
\pm \\
2.73\end{array}$ & $\begin{array}{c}59.71^{\mathrm{ab}} \\
\pm \\
2.36\end{array}$ & $\begin{array}{c}59.57^{\mathrm{b}} \\
\pm \\
2.27\end{array}$ & $\begin{array}{c}63.14^{\mathrm{a}} \\
\pm \\
2.11\end{array}$ & $\begin{array}{c}62.57^{\mathrm{a}} \\
\pm \\
3.15\end{array}$ & $\begin{array}{c}64.71^{\mathrm{a}} \\
\pm \\
2.11\end{array}$ & $\begin{array}{c}61.30^{\mathrm{a}} \\
\pm \\
2.40\end{array}$ & $\begin{array}{c}62.43^{\mathrm{a}} \\
\pm \\
1.49\end{array}$ & $\begin{array}{c}63.86^{\mathrm{a}} \\
\pm \\
3.56\end{array}$ & $\begin{array}{c}64.86^{\mathrm{a}} \\
\pm \\
2.82\end{array}$ & $\begin{array}{c}62.00^{\mathrm{a}} \\
\pm \\
1.67\end{array}$ & $\begin{array}{c}63.00^{\mathrm{a}} \\
\pm \\
2.08\end{array}$ & $\begin{array}{c}61.00^{\mathrm{a}} \\
\pm \\
1.23\end{array}$ & $* *$ \\
\hline $\begin{array}{c}\text { NEFA } \\
(\mathrm{mMol} / \mathrm{L}\end{array}$ & $\begin{array}{c}0.41^{\text {abcd }} \\
\pm \\
0.18\end{array}$ & $\begin{array}{c}0.41^{\text {abcd }} \\
\pm \\
0.21\end{array}$ & $\begin{array}{c}0.21^{\text {bcd }} \\
\pm \\
0.08\end{array}$ & $\begin{array}{c}0.52^{\mathrm{abc}} \\
\pm \\
0.22\end{array}$ & $\begin{array}{c}0.64^{\mathrm{ab}} \\
\pm \\
0.20\end{array}$ & $\begin{array}{c}0.88^{\mathrm{a}} \\
\pm \\
0.28\end{array}$ & $\begin{array}{c}0.24^{\text {bcd }} \\
\pm \\
0.06\end{array}$ & $\begin{array}{c}0.38^{\text {bcd }} \\
\pm \\
0.17\end{array}$ & $\begin{array}{c}0.13^{\text {cd }} \\
\pm \\
0.01\end{array}$ & $\begin{array}{c}0.12^{\text {cd }} \\
\pm \\
0.01\end{array}$ & $\begin{array}{c}0.18^{\text {bcd }} \\
\pm \\
0.06\end{array}$ & $\begin{array}{c}0.14^{\mathrm{cd}} \\
\pm \\
0.01\end{array}$ & $\begin{array}{c}0.42^{\text {abcd }} \\
\pm \\
0.12\end{array}$ & $\begin{array}{c}0.36^{\text {bdd }} \\
\pm \\
0.11\end{array}$ & $\begin{array}{c}0.25^{\text {bcd }} \\
\pm \\
0.04\end{array}$ & $\begin{array}{c}0.24^{\mathrm{bcd}} \\
\pm \\
0.05\end{array}$ & $\begin{array}{c}0.21^{\text {bcd }} \\
\pm \\
0.06\end{array}$ & $\begin{array}{c}0.22^{\text {bcd }} \\
\pm \\
0.04\end{array}$ & $\begin{array}{c}0.40^{\text {bed }} \\
\pm \\
0.25\end{array}$ & $\begin{array}{c}0.50^{\text {abcd }} \\
\pm \\
0.26\end{array}$ & $\begin{array}{c}0.47^{\mathrm{bcd}} \\
\pm \\
0.21\end{array}$ & $\begin{array}{c}0.32^{\text {cd }} \\
\pm \\
0.09\end{array}$ & $\begin{array}{c}0.12^{\text {cd }} \\
\pm \\
0.07\end{array}$ & $*$ \\
\hline $\begin{array}{c}\text { Calcium } \\
\text { (mg/dl) }\end{array}$ & $\begin{array}{c}8.90^{\mathrm{ab}} \\
\pm \\
0.80\end{array}$ & $\begin{array}{c}8.53^{\mathrm{ab}} \\
\pm \\
0.82\end{array}$ & $\begin{array}{c}8.47^{\mathrm{ab}} \\
\pm \\
0.65\end{array}$ & $\begin{array}{c}7.93^{\mathrm{ab}} \\
\pm \\
0.53\end{array}$ & $\begin{array}{c}8.55^{\mathrm{ab}} \\
\pm \\
0.87\end{array}$ & $\begin{array}{c}9.47^{\mathrm{ab}} \\
\pm \\
0.73\end{array}$ & $\begin{array}{c}9.17^{\mathrm{ab}} \\
\pm \\
0.69\end{array}$ & $\begin{array}{c}8.65^{\mathrm{ab}} \\
\pm \\
0.64\end{array}$ & $\begin{array}{c}8.41^{\mathrm{ab}} \\
\pm \\
0.54\end{array}$ & $\begin{array}{c}10.66^{\mathrm{a}} \\
\pm \\
0.70\end{array}$ & $\begin{array}{c}9.26^{\mathrm{ab}} \\
\pm \\
0.70\end{array}$ & $\begin{array}{c}8.38^{\mathrm{ab}} \\
\pm \\
0.52\end{array}$ & $\begin{array}{c}8.67^{\mathrm{ab}} \\
\pm \\
0.36\end{array}$ & $\begin{array}{c}8.83^{\mathrm{ab}} \\
\pm \\
0.19\end{array}$ & $\begin{array}{c}9.78^{\mathrm{a}} \\
\pm \\
0.63\end{array}$ & $\begin{array}{c}9.52^{\mathrm{ab}} \\
\pm \\
0.52\end{array}$ & $\begin{array}{c}9.79^{\mathrm{a}} \\
\pm \\
0.84\end{array}$ & $\begin{array}{c}8.72^{\mathrm{ab}} \\
\pm \\
0.37\end{array}$ & $\begin{array}{c}10.45^{\mathrm{a}} \\
\pm \\
0.46\end{array}$ & $\begin{array}{c}9.02^{\mathrm{ab}} \\
\pm \\
0.36\end{array}$ & $\begin{array}{c}9.58^{\mathrm{ab}} \\
\pm \\
0.44\end{array}$ & $\begin{array}{c}7.94^{\mathrm{ab}} \\
\pm \\
0.74\end{array}$ & $\begin{array}{c}9.49^{\mathrm{ab}} \\
\pm \\
0.42\end{array}$ & $* *$ \\
\hline $\begin{array}{c}\text { Phosphorus } \\
\text { (mg/dl) }\end{array}$ & $\begin{array}{c}4.38^{\text {abcdo }} \\
\pm \\
0.42\end{array}$ & $\begin{array}{c}4.45^{\text {abcde }} \\
\pm \\
0.44\end{array}$ & $\begin{array}{c}4.66^{\text {abcde }} \\
\pm \\
0.32\end{array}$ & $\begin{array}{c}4.99^{\text {abcd }} \\
\pm \\
0.23\end{array}$ & $\begin{array}{c}5.16^{\text {abcd }} \\
\pm \\
0.31\end{array}$ & $\begin{array}{c}4.31^{\text {abcde }} \\
\pm \\
0.42\end{array}$ & $\begin{array}{c}4.93^{\mathrm{abcc}} \\
\pm \\
0.54\end{array}$ & $\begin{array}{c}5.32^{\mathrm{abc}} \\
\pm \\
0.38\end{array}$ & $\begin{array}{c}5.93^{\mathrm{a}} \\
\pm \\
0.80\end{array}$ & $\begin{array}{c}4.24^{\text {abcde }} \\
\pm \\
0.47\end{array}$ & $\begin{array}{c}5.65^{\mathrm{ab}} \\
\pm \\
0.65\end{array}$ & $\begin{array}{c}4.67^{\text {abcde }} \\
\pm \\
0.53\end{array}$ & $\begin{array}{c}4.26^{\text {abcde }} \\
\pm \\
0.35\end{array}$ & $\begin{array}{c}4.27^{\text {abcde }} \\
\pm \\
0.32\end{array}$ & $\begin{array}{c}3.58^{\text {cde }} \\
\pm \\
0.21\end{array}$ & $\begin{array}{c}4.03^{\text {bcde }} \\
\pm \\
0.46\end{array}$ & $\begin{array}{c}3.82^{\text {cde }} \\
\pm \\
0.39\end{array}$ & $\begin{array}{c}3.65^{\text {cde }} \\
\pm \\
0.26\end{array}$ & $\begin{array}{c}4.35^{\text {abcdo }} \\
\pm \\
0.31\end{array}$ & $\begin{array}{c}3.61^{\mathrm{cde}} \\
\pm \\
0.42\end{array}$ & $\begin{array}{c}4.36^{\text {abcde }} \\
\pm \\
0.30\end{array}$ & $\begin{array}{c}4.37^{\text {abcd }} \\
\pm \\
0.54\end{array}$ & $\begin{array}{c}5.08^{\text {abcd }} \\
\pm \\
0.41\end{array}$ & $* *$ \\
\hline $\begin{array}{c}\text { Magnesium } \\
\text { (mg/dl) }\end{array}$ & $\begin{array}{c}1.98^{\text {gh }} \\
\pm \\
0.09\end{array}$ & $\begin{array}{c}2.40^{\text {efgh }} \\
\pm \\
0.14\end{array}$ & $\begin{array}{c}2.26^{\mathrm{gh}} \\
\pm \\
0.17\end{array}$ & $\begin{array}{c}2.16^{\text {gh }} \\
\pm \\
0.13\end{array}$ & $\begin{array}{c}2.33^{\text {fgh }} \\
\pm \\
0.15\end{array}$ & $\begin{array}{c}2.56^{\text {defg }} \\
\pm \\
0.10\end{array}$ & $\begin{array}{c}3.56^{\mathrm{bcd}} \\
\pm \\
0.39\end{array}$ & $\begin{array}{c}2.90^{\text {cdefg }} \\
\pm \\
0.14\end{array}$ & $\begin{array}{c}3.28^{\text {bdef }} \\
\pm \\
0.12\end{array}$ & $\begin{array}{c}2.84^{\text {defg g }} \\
\pm \\
0.13\end{array}$ & $\begin{array}{c}2.89^{\text {cdefg }} \\
\pm \\
0.11\end{array}$ & $\begin{array}{c}3.35^{\text {bcde }} \\
\pm \\
0.36\end{array}$ & $\begin{array}{c}4.71^{\mathrm{a}} \\
\pm \\
0.24\end{array}$ & $\begin{array}{c}3.54^{\text {bcd }} \\
\pm \\
0.32\end{array}$ & $\begin{array}{c}3.92^{\mathrm{ab}} \\
\pm \\
0.32\end{array}$ & $\begin{array}{c}3.66^{\mathrm{bc}} \\
\pm \\
0.16\end{array}$ & $\begin{array}{c}3.68^{\mathrm{bc}} \\
\pm \\
0.22\end{array}$ & $\begin{array}{c}3.61^{\mathrm{bc}} \\
\pm \\
0.30\end{array}$ & $\begin{array}{c}3.73^{\mathrm{bc}} \\
\pm \\
0.20\end{array}$ & $\begin{array}{c}2.78^{\text {cdefg }} \\
\pm \\
0.14\end{array}$ & $\begin{array}{c}3.29^{\text {cdef }} \\
\pm \\
0.46\end{array}$ & $\begin{array}{c}3.51^{\text {cde }} \\
\pm \\
0.45\end{array}$ & $\begin{array}{c}3.15^{\text {cdef }} \\
\pm \\
0.36\end{array}$ & $* *$ \\
\hline
\end{tabular}

Means ${ }^{\text {abcdefg }}$ having different superscripts in row differ significantly

* Significance at $\mathrm{P}<0.05, \quad * *$ Significance at $\mathrm{P}<0.01$ 
In Sahiwal cows values increased up to day 199 and then variation slightly till day 287 and slightly increased end of lactation. Similar finding were observed by Kulkarni, et al., (1993) and Piccoine, et al., (2012) reported significant decreased all stages of lactation. Castillo et al., (1994) significant variation was observed in phosphorus levels during various stages of lactation. Kulkarni, et al., (1983) and Shrikhande, et al., (2001) noted nonsignificant effect of parity of animals on phosphorus concentration, however Talvelkar, et al., (2007) reported phosphorus levels declined during early stage of lactation.

The mean values of serum $\mathrm{Mg}$ concentration ranges from $1.98 \pm 0.09$ to $4.71 \pm 0.24 \mathrm{mg} / \mathrm{dl}$ during complete lactation in Sahiwal cows. In Sahiwal cows $\mathrm{Mg}$ level the trend was slightly increases from beginning to end of lactation. The results are in agreement with those of Pyne and Maitra (1981) who observed nonsignificant change in $\mathrm{Mg}$ during the lactation period. Shrikhande, et al., (2001) observed higher magnesium level upto third lactation, whereas, lower $\mathrm{Mg}$ level was observed after $6^{\text {th }}$ lactation.

\section{Acknowledgement}

Author are thankful to College of Veterinary Science and Animal Husbandry Anjora, Durg, Chhattisgarh and The assistant provided for my research programme from Board of Research and Nuclear Sciences (BRNS), BARC, Mumbai under Project No. 2013/35/15/BRNS is gratefully acknowledged.

\section{References}

Arora, S. P. and Gupta, B. S. 1969. Variation in the milk components of Nimari cows. Indian J. Dairy Sci. 22: 65-67.

Bahiram, K. B., Khan, J. R., Ingole, S. D., Kumarswamy, J and Gade, N. E. $2018^{\mathrm{a}}$. Relationship between certain hormones, metabolites and milk composition during complete lactationin HF crossbred cows. J. Bombay Vet. Coll. 25(1):7-9.

Bahiram, K. B., Khan, J. R. and Korde, J. P. $2018^{\mathrm{b}}$. Correlation between milk production Traits, certain hormones and serum biochemical parameters in lactating Murrah buffaloes. Indian J. Vet. Sci. Biotech. 12(3):90-93.

Bajwa, I. R., Khan, M. S., Khan, M. A. and Gondal, K. Z. 2004. Environmental factors affecting milk yield and lactation length in Sahiwal cattle. Pak. Vet. J. 24. 23-27.

Balakrishnan, M., Ramesha, K. P. and Chinnaiya, G. P. 1997. Effect of post partum body condition loss on performance in crossbred cows - an assessment through body condition scoring. Indian J. Dairy Sci. 50: 393397.

Bhonsle, D., Chourasia, S. K., Singh, M. and Jain, R. K. 2003. Factors influencing major milk constituents in Murrah buffaloes. Indian J. Anim. Sci. 73: 107109.

Broster, W. H. and Broster, V. J. 1998. Body score of dairy cows. J. Dairy Res. 65:155.

Broucek, J., Novak, P., Vokralova, J., Soch, M., Kisac, P. and Uhrincat, M. 2009. Effect of high temperature on milk production of cows from free -stall housing with natural ventilation. Slovak J. Anim. Sci. 42: $167-173$.

Bruno, M. M., Melina, M. Y., Fabio, C. P., Henderson, A., Rinaldo, B. V. and Eduardo H. B. J. 2012. Lipid and glucose profiles of dairy Buffaloes during lactation and dry period. Amazonian J. Agri. And Envir. Sci. 55(1):33-39.

Castillo, C., Benedito, J. L., Hernandez, J., Fidalgo, L. E., Dize-Prieto, I., Valliso, M., Prieto, I. D. and Trenti, F. 1994. Variation factors of variables in bovine physiology III minerals and trace 
elements. Proceeding 18th World Buiatrics Congress of Italian Association of Buiatrics, Bolonga, Italy, August 29th - Sept. 2nd, Pp. 463-466.

Chawla, D. S. and Mishra, R. R. 1976. Inheritance of milk fat content in Red Sindhi, Sahiwal and their Brown crosses. Indian J. Dairy Sci. 29:179183.

Dahate, M. M., Mishra, O. P., Khan, J. R., Gawande, M. L. and Tiwari, S. K. 2004. Comparative study of certain physiological and biochemical parameters in pregnant, lactating and dry Sahiwal cows. Indian Vet. Med. J. 28:217-220.

Dalvi, S. H., Deshmukh, B. T., Mantri, A. and Talvelkar, B. A. 1995. Concentration of blood serum thyroid hormones during late pregnancy, parturition and early lactation of crossbred cows. Indian $\mathrm{J}$. Anim. Sci. 65 (1): 15-19.

Dechow, C. D., Rogers, G. W., Klei, L. and Lawlor, T. J. 2003. Heritabilities and correlations among body condition score, dairy form and selected linear type traits. J. Dairy Sci. 86:2236.

Deshmukh, B. T. and Mantri, A. 1997. Thyroid hormones concentration during lactation in cows. Indian J. Anim. Sci. 67 (10): 880-881.

Domecq, J. J., Skidmore, A. L., Lloyd, J. W. and Kaneene, J. B. 1997. Relationship between body condition scores and milk yield in a large dairy herd of high yielding Holstein cows. J. Dairy Sci. 80:101-112.

Elanco, 1996. Body condition scoring in dairy cattle. Elanco Animal Health Bulletin AI 8478. Elanco Animal Health, Greenfield, IN.

Epaphras, A., Karimuribo, E. D. and Msellem, S. N. 2004. Effect of season and parity on lactation of crossbred Ayrshire cows reared under coastal tropical climate in Tanzania. Livestock Research for Rural Development. 16: 752-758.

Ferguson, J. D. 1996. Implementation of body condition scoring program in dairy herds. Feeding and managing the transition cow. Proc. Penn. Annu. Conf., Univ. of Pennsylvania, Centre for Animal Health and Productivity, Kennett Square, PA.

Ferguson, J. D., Galligan, D. T. and Thomsen, N. 1994. Principal descriptors of body condition score in Holstein cows. J. Dairy Sci. 77:2695-2703.

Garnsworthy, P. C. and Topps, J. H. 1982. The effect of body condition of dairy cows at calving on their food intake and performance when given complete diets. Anim. Prod. 35:113.

Gearhart, M. A., Curtis, C. R., Erb, H. N., Smith, R. D., Sniffen, C. J., Chase, L. E. and Cooper, M. D. 1990. Relationship of changes in condition score to cow health in Holsteins. J. Dairy Sci. 73:3132.

Ingvartsen, K. L. 2006. Feeding-and management-related diseases in the transition cow Physiological adaptations around calving and strategies to reduce feeding-related diseases. Anim. Feed Sci. and Tech. 126: 175-213.

Jacob, N., Arya, J. S. and Gajbhiye, P. U. 2014. Correlation between milk and plasma components in gir cattle and jaffarabadi buffaloes during different lactation stages. Indian J. Dairy Sci. 67(1):59-64.

Jindal, S. K. and Ludri, R. S. 1990 ${ }^{\mathrm{a}}$. Growth hormone concentrations in lactating crossbred cows and buffaloes A. J. Anim. Sci. 3(4):319-322.

Jindal, S. K. and Ludri, R. S. $1990^{\mathrm{b}}$. Insulin concentrations in lactating crossbred cows and buffaloes. Indian J. Anim. Sci. 5: 249-252

Jindal, S. K. and Ludri, R. S. 1994. Relationship between some circulating hormones, metabolites and milk yield in lactating crossbred cows and buffaloes. A. J. Anim. Sci. 7(2):239-248.

Kamboz, M. L., Singh, A. and Prasad, S. 2007. Effect of udder and teat shapes and their measurements on Somatic cell counts in milk of Karan Fries cows. Indian J. Dairy Sci. 60: 435-440. 
Kataria, A. K. and Kataria, N. 2006. A comparison of somatic cell counts in milk from Rathi and Holstein Friesian cattle. The Indian Cow. 1: 3-5.

Kaushik, S. N. 1970. Genetic studies on the content of milk fat milk protein and solid-not-fat in milk from in Hariana cattle. Ph. D. Thesis Agric. Univ., Agra.

Kennedy, B. W., Sethar, M. S., Moxley, J. E. and Downey, B. R. 1982. Environmental factors influencing testday somatic cell counts in Holstiens. J. Dairy Sci. 65: 275-280.

Khan, H. M., Mohanty, T. K., Raina, V. S. and Gupta, A. K. 2011. Relationship of blood metabolites with reproductive parameters during various seasons in Murrah buffaloes. Asian-Aust. J. Anim. Sci. 24 (9): 1192-1198.

Khan, J. R. 1998. Circulatory level of some hormones, metabolites and haematological parameters during pregnancy in crossbred goats. Ph.D. Thesis. National Dairy Research Institute (Deemed Univ.), Karnal, India.

Khan, J. R. and Ludri, R. S. 2002. Changes in blood glucose, plasma non-esterified fatty acids and insulin in pregnant and non-pregnant goats. Tropical Anim. Health and Prod. 34:81-90.

Kulkarni, B. A., Talvelkar, B. A., Deshmukh, B. T., Kolhatkar, V. P., Patankar, D. D., Gokani, S. S. and Kulkarni, B. S. 1983. Biochemical studies in Gir and crossbred dairy cows. Indian Vet. J. 60: 17-22.

Kulkarni, B. A., Talvelkar, B. A., Kaushik, R. V., Gokani, S. S., Patankar, D. D. and Kulkarni, B. S. 1993. Blood metabolic profiles in crossbred lactating cows. Indian J. Anim. Sci. 63: 716-719.

Kumaresan, G. 2013. Somatic cell pattern and composition of milk of Holstein Friesian cross bred cattle. Int. J. Sci., Envir. and Tech. 2 (6):1421-1425.

Kumaresan, G. 2014. Somatic cell pattern and composition of milk of Jersey cross bred cattle. Indian Vet. J. 91(10):38-40.

Manzoor, M., Deshmukh, B. T., Joshi, V. G.,
Kulkarni, B. A., Talvelkar, B. A., Pahuja, D. N., Borkar, A. V. and Samual, A. M. 1994. Concentration of some major elements in blood plasma and milk of crossbred cows during different stages of lactation. Indian $\mathrm{J}$. Dairy Sci. 47: 94-98.

Mathapati, S. S. and Bhat, G. S. 1988. Composition and some properties of milk from cross breed cows. Indian J. Dairy Sci. 41:171-175.

Mishra, A., Pankaj, P. K. and Prakash, B. S. 2007. Comparative status of blood metabolites with commencement of cyclicity in post-partum lactating riverine buffaloes (Bubalus bubalis). J. Dairying, Foods and H.S. 26 (3/4): 164168.

Nagre S. M., Kuralkar Prajakta, Dhenge S.A. and Kuralkar S.V. 2013. Relation of leptin, insulin and glucose during late gestation and early lactation in murrah buffalo. Proc. XXII Annual Conference of Society of Animal Physiologists of India (SAPI) and National Symposium, Mathura, November 19-21, Pp 57.

Nigam, S. and Bector, B. S. 1991. Effect of milking and stage of lactation on the composition of milk of crossbred (Karan-Swiss and Karan-Fries) and Sahiwal cattle. Indian J. Dairy Sci. 44:431-434.

Oudah, E. Z. 2009. Non-genetic factors affecting somatic cell count, milk urea content, test-day milk yield and milk protein percent in dairy cattle of the Czech Republic using individual testday records. Live. Res. for Rural Dev. 21: (5)

Ouedraogo, G. A., Millogo, V., Anago-Sidibe, A. G. and Kanwe, B. A. 2008. Relationship between somatic cell counts, dairy cattle milk yield and composition in Burkina Faso. African J. Biochem. Res. 2: 56-60.

Overton, T. R. 2003. Managing the Metabolism of Transition Cows. Proceedings of the 6th Western Dairy Management Conf. March 12-14, Pp 7. 
Phukan, M., Baruah, A., Sharma, B.C., Baruah, K.K. and Kalita, D. J. 2000. Serum macro and micro mineral levels in crossbred (Jersey $\mathrm{X}$ Assam Local) calves during pre-weaning and postweaning periods. Indian Vet. J. 77: 583585.

Piccione, G., Messina, V., Marafioti, S., Casella, S., Giannetto, C. And Fazio, F. 2012. Changes of some haematochemical parameters in dairy cows during late gestation, post partum, lactation and dry periods. Vet. Med. Zoot. 58(80):59-64.

Pradhan, N. R. and Chakraborti, A. 1986. Blood glucose and calcium profile in crossbred cows with relation to lactation. Indian J. Vet. Met. 6: 60-61.

Pyne, A. K. and Maitra, D. N. 1981. Physiological studies on blood of lactation Hariana and Sahiwal cattle. Indian Vet. J. 58: 526-528.

Pyorarla, S. 2003. Indicators of inflammation in the diagnosis of mastitis. Vet. Res. 34:565-578.

Rao, K. S. and Anitha, A. 2004. Body condition score (BCS) system-An ideal management tool for dairy cow production. Ind. Dairyman. 56:49.

Rawat, B., Nigam, R. and Jain, A.K. 2006. Metabolic profile in late pregnancy and early lactation in Hariana and crossbred cows. Indian Vet. J. 83: 795-797.

Rook, J. A. and Campling, R. C. 1965. Effect of stage and number of lactation on the yield and composition of cow's milk. J. Dairy Res. 32:45-55.

Ruegg, P. L. and Milton, R. L. 1995. Body condition scores of Holstein cows on Prince Edward Island, Canada: Relationships with yield, reproductive performance, and disease. J. Dairy Sci. 78:552.

Saxena, M. M., Suman, C. L., Katpatal, B. G. and Pandey, H. S. 1997. study of milk constituents and their yields in Holstein Friesian cows. Indian J. Anim. Prod. Mgmt.13:127.

Schroder, U. J. and Staufenbiel, R. 2006.
Invited review: Methods to determine body fat reserves in the dairy cow with special regard to ultrasonographic measurement of backfat thickness. J. Dairy Sci. 89:1.

Schutz, M. M., Hansen, L. B., Steuerngal, G.R. and Kuck, A. L. 1990. Vearitation of Milk fat, protein and somatic cells for dairy cattle. J. Dairy Sci. 73:484.

Sharma, A. K., Wilcox, C. J., Martin, F. G. and Thatcher, W. W. 1990. Effect of stage of lactation and pregnancy and their interaction on milk yield and constituents. J. Dairy Sci. 73:1586.

Sharma, R. B., Kumar, M. and Pathak, V. 2002. Effect of different seasons on cross-bred cow milk composition and paneer yield in Sub-Himalayan region. Asian-Aust. J. Anim. Sci. 15: 528- 530.

Shipe, W. F., Senyk, G. F. and Fountain, K. B. 1980. Modified soap solvent extraction method for measuring free fatty acids in milk. J. Dairy Sci. 63:193-198.

Shrikhande, G. B., Vhora, S. C. and Jangde, C. R. 2001. Haemato-biochemical studies in different parity groups of cows. The Veterinarian. 25: 1-2.

Singh, B. B. 1979. Effect of season on chemical composition of milk. Indian Vet. J. 56:768-771.

Singh, M. and Dang, A. K. 2002. Somatic cell counts of milk, National Dairy Res. Institute, Karnal India. Publication No: $1 / 2002$.

Singh, M. and Ludri, R. S. 2001. Influence of lactation, parity and season on somatic cell counts in cows. Asian-Aust. J. Anim. Sci. 14:1775-1780.

Singh, M. and Ludri, R. S. 2002. Milk production, blood metabolites and circulatory levels of hormones in crossbred goats. Asian-Aust. J. Anim Sci. 15(7): 963-967.

Snedecor, G. W. and Cochran, W. G. 1994. Statistical Methods. 8th edn. Oxford and IBH. The Iowa State University Press, Ames, Iowa, USA.

Spicer, L. J. Geisert, R. D. and Cochran, W. G. 1990. Concentration of insulin-like 
growth factor-1. Oestradiol and progesterone in follicular fluid of ovarian follicles during early pregnancy in cattle. Theriogenology. 37: 749-760.

SPSS., 2015. SPSS for Windows Release 20.0 Version. SPSS Inc., USA.

Sudhakar, K., Panneerselvam, S., Thiruvenkadan, A. K., Abraham, J., and Vinodkumar, G. 2013. Factors effecting milk composition of crossbred dairy cattle in southern India. Int. J. Food, Agri. and Vet. Sci. 3: 229-233.

Talvelkar, B. A., Patil, R. R., Ingole, S. D. and Bharucha, S. V. 2007. Macroelement profile of buffaloes during gestation, lactation and peripartum period. J. Bombay Vet. Coll. 15 (1 \& 2): 10-14.

Treacher, R. J., Reid, J. M. and Roberts, C. J. 1986. Effect of body condition at calving on the health and performance of dairy cows. Anim. Prod. 43:1-6.

Venkatachelapathy, R. T. and Iype, S. 1998. Fat, total solids and solids-not fat percentage of milk in Vechur cattle.
Indian J. Anim. Sci. 68:570.

Voigtlander, K. H. and Bothen, S. 1979. Lactose contents of cow's milk and its variability. Anim. Breed. Abstr. 47:1710.

Weglarz A., Gardzina-Mytar, E., Zapletal, P., Makulska, J. and Frelich, J 2008. Effect of the parity, lactation stage and season of feeding on the somatic cell count in cow milk. J. Agrobiology. 25 (2): 209214.

Yadav, P. L., Nautiyal, P. L., Saxena, M. M., Sanyal, M. K. Dubey, P. C., Pandey, H. S. Nivsaikar, A. E. and Bhat, P. N. 1991. Quality characteristics of milk from Holstein Friesian and Hariana $\mathrm{x}$ Exotic cattle. Indian Vet. J. 68: 963.

Yogi, S., Choursia, S. K., Sahu, S. S. and Jaiswal, S. 2017. Correlation between milk constituents and somatic cell counts in Holstein Friesian crossbred cattle. Int. J. Agri. Sci. 9(7): 3840-3842.

\section{How to cite this article:}

Bahiram, K. B., J. R. Khan, N. E. Gade, M. K. Gendley, M. S. Patil and Kumarsamy, J. 2020. Studies on Milk Yield, Milk Composition, Circulating Hormones, Energy Metabolites and Biochemical Parameters during Complete Lactation in Sahiwal Cows. Int.J.Curr.Microbiol.App.Sci. 9(09): 1586-1599. doi: https://doi.org/10.20546/ijcmas.2020.909.198 